\title{
THE SKULL OF CHAMAELEO NASUTUS ADDS MORE INFORMATION TO THE RELATIONSHIP OF CHAMAELEO WITH RHAMPHOLEON AND BROOKESIA (CHAMAELEONIDAE, REPTILIA)
}

\author{
by \\ D. HILLENIUS $\dagger$ \\ Institute of Taxonomic Zoology (Zoölogisch Museum), University of Amsterdam, \\ P.O. Box 4766, 1009 AT Amsterdam, The Netherlands
}

\begin{abstract}
The form of the skull of Chamaeleo nasutus, especially the broad, trigonal parietal, is strikingly similar to the skull of Rhampholeon. This supports the hypothesis (Hillenius, 1986) that of all chameleons the group of species around Ch. nasutus is the most closely related to Rhampholeon.

\section{RÉSUMÉ}

Le crâne de Chamaeleo nasutus est absolument similaire à celui de Rhampholeon, ce qui est surtout valable pour le pariétal qui est large et triangulaire. Ceci vient à l'appui de l'hypothèse (Hillenius, 1986) que les Caméléons les plus étroitement apparentés à Rhampholeon sont ceux du groupe d'espèces gravitant autour de $C h$. nasutus.
\end{abstract}

\section{INTRODUCTION}

On several occasions it has been pointed out that Brookesia Gray, 1864 and Rhampholeon Günther, 1874 share a number of characters with the group of species around Chamaeleo nasutus Duméril \& Bibron, 1836. Klaver (1979) argued that the agreements were parallellisms but in fact he did not provide the arguments for this assumption. In a later paper Klaver (1981) concluded that Chamaeleo was derived from Brookesia.

† Note added by A. Zuiderwijk. - Dr. D. Hillenius unexpectedly died on May 4th, 1987. This posthumous publication contributes to the discussion on the taxonomy of chameleons, as did the main part of his scientific work.

The text of this paper is, in essential, an unchanged manuscript that was found in his papers. Drs. W. Bergmans was helpful to select the skulls for the illustrations. Mr. L. van der Laan made the photographs and Mr. J. Zaagman composed the figures. We thank Drs. $\mathrm{Ch}$. Klaver for making some nomenclatural corrections in the manuscript.
In a foregoing paper on the relationships of Brookesia and Rhampholeon with Chamaeleo (Hillenius, 1986) I concluded that both former genera are derived from Chamaeleo and that the probably nearest relatives can be found in the group of species around $C h$. nasutus.

Microcomplement fixation has confirmed the first part of this conclusion: Brookesia and Rhampholeon - probably originally in one taxon have split off from Chamaeleo long after other branches of Chamaeleo originated (Hofman et al., in press).

The skulls of Rhampholeon and Brookesia, however, differ considerably from all Chamaeleo skulls that were examined until recently. So I considered it of importance to obtain a skull of a member of the group of species around $C h$. nasutus to see if any indication of relationship to the deviating form of skulls of Rhampholeon and/or Brookesia might be found.

\section{MATERIAL AND METHOD}

Thanks to the courtesy of Dr. E. R. Brygoo, curator of the herpetological department of the Muséum National d'Histoire Naturelle in Paris, I received in exchange a specimen of Chamaeleo nasutus. The skull was carefully macerated in the Zoological Museum of Amsterdam and inscribed under number 16170 . It has been compared to skulls of representatives of all the species groups belonging to Chamaeleo (as described by Klaver, 1981), and to representatives of the group Brookesia + Rhampholeon. Skulls of the following specimens, all with the collection number of the Zoological Museum of Amsterdam, have been examined in detail:

Chamaeleo basiliscus no. 15223, Ch. chamaeleon no. 10267, Ch. fischeri no. 14409, Ch. jacksonii no. 16172, Ch. johnstoni no. $15216, C h$. lateralis no. $10168, C h$. montium no. 16174 , Ch. nasutus no. 16170, Ch. oustaleti no. 15215 and no. 10165, Ch. oweni no. 15221, Ch. pardalis no. 14332, Ch. 


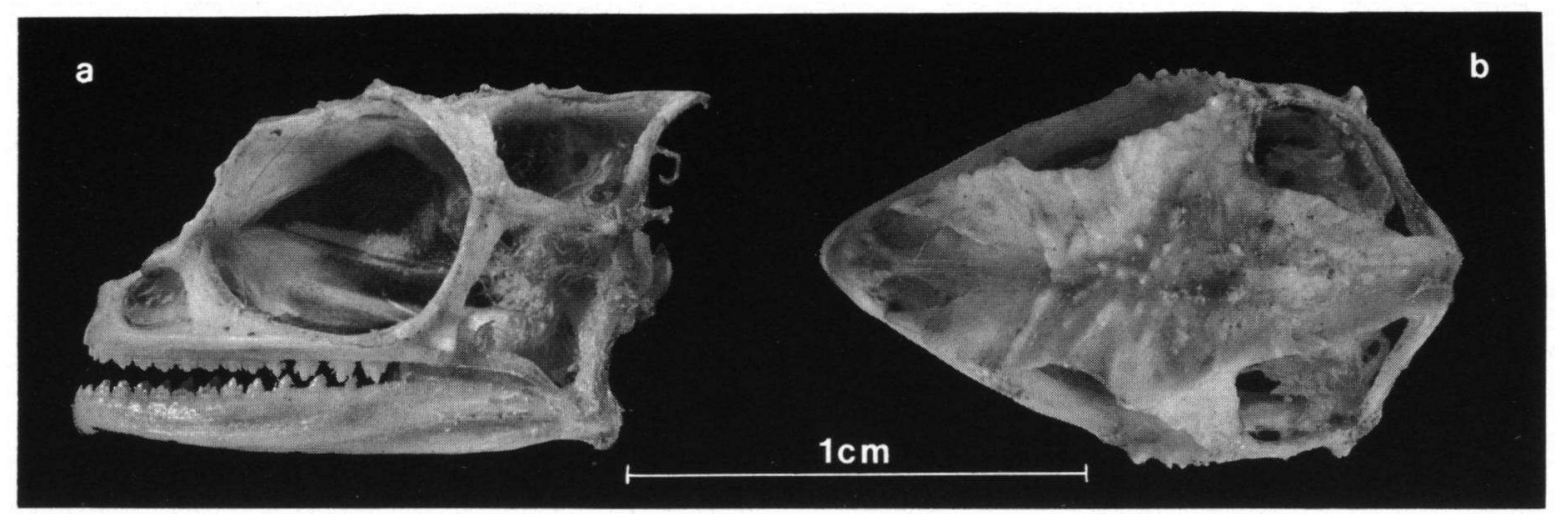

Fig. 1. Rhampholeon spectrum, lateral view (a) and dorsal view (b) of the same skull.

pumilus no. 15217, Ch. senegalensis no. 15224, Ch. tigris no 16173, Ch. zeylanicus no. 15222, Rhampholeon kerstenii no 15565, and Rh. spectrum no. 10264.

\section{DESCRIPTION AND DISCUSSION}

The skull of Chamaeleo nasutus proves to be quite different from skulls of other chameleons of the genus Chamaeleo (see figs. 2 and 3), and less different from skulls of members of Klaver's group A, consisting of Brookesia and Rhampholeon. The likeness of the nasutus skull with that of Rhampholeon in particular is striking (see figs. 1 and 2).

In most chameleons the parietal is a narrow crestlike bone, horizontally straight or curved in a vertical plane. We find this type of skull in (see fig. 3):

group B: Ch. oustaleti Mocquard, 1894, Ch. lateralis Gray, 1831, Ch. pardalis Cuvier, 1829, Ch. fischeri Reichenow, 1887 and Ch. tigris Kuhl, 1820;

group C: Ch. chamaeleon (Linnaeus, 1758), Ch. chamaeleon zeylanicus Laurenti, 1768, Ch. basiliscus Cope, 1868, and Ch. senegalensis Daudin, 1802;

group E: Ch. oweni Gray, 1831, Ch. montium Buchholz, 1874, and Ch. johnstoni Boulenger, 1901;

group F: Ch. jacksonii Boulenger, 1896, Ch. bitaeniatus Fischer, 1884, Ch. hoehnelli Steindachner, 1891, and Ch. ellioti Günther, 1895.

The only deviating skull known until now was Ch. pumilus c.s. (group B, see fig. 4), in which the parietal forms a broad bone with parallel lateral borders. This parietal was one of the main arguments of several herpetologists (among whom most South Africans, see Raw,

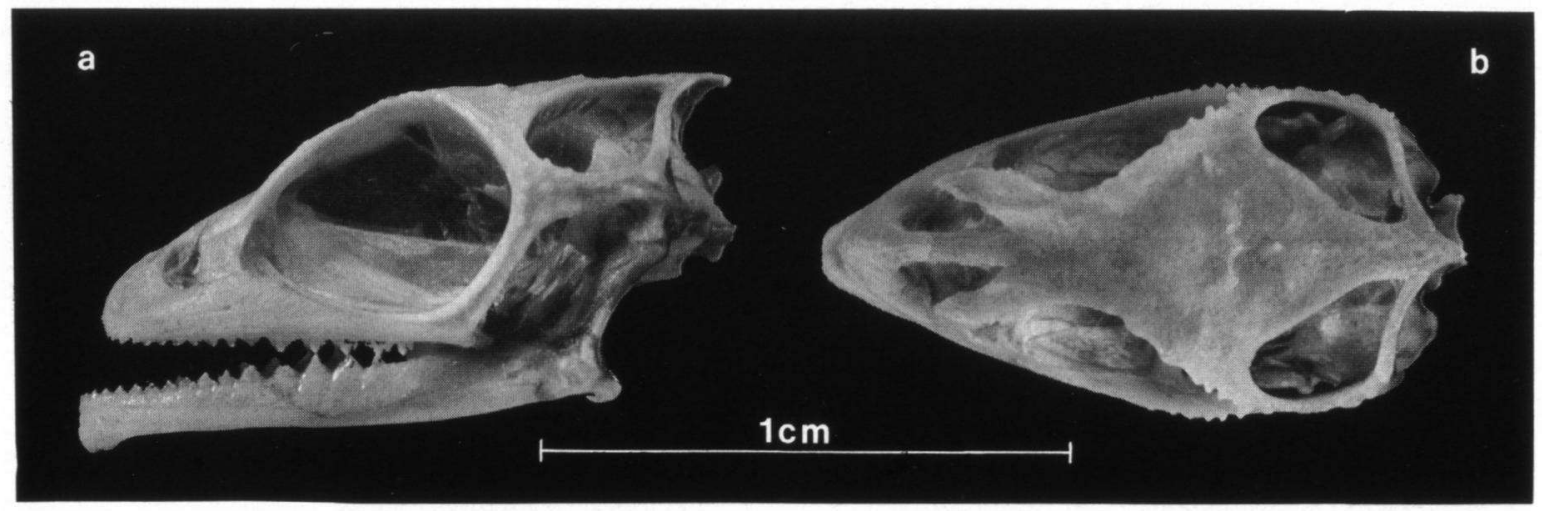

Fig. 2. Chamaeleo nasutus, lateral (a) and dorsal view (b) of the same skull. 

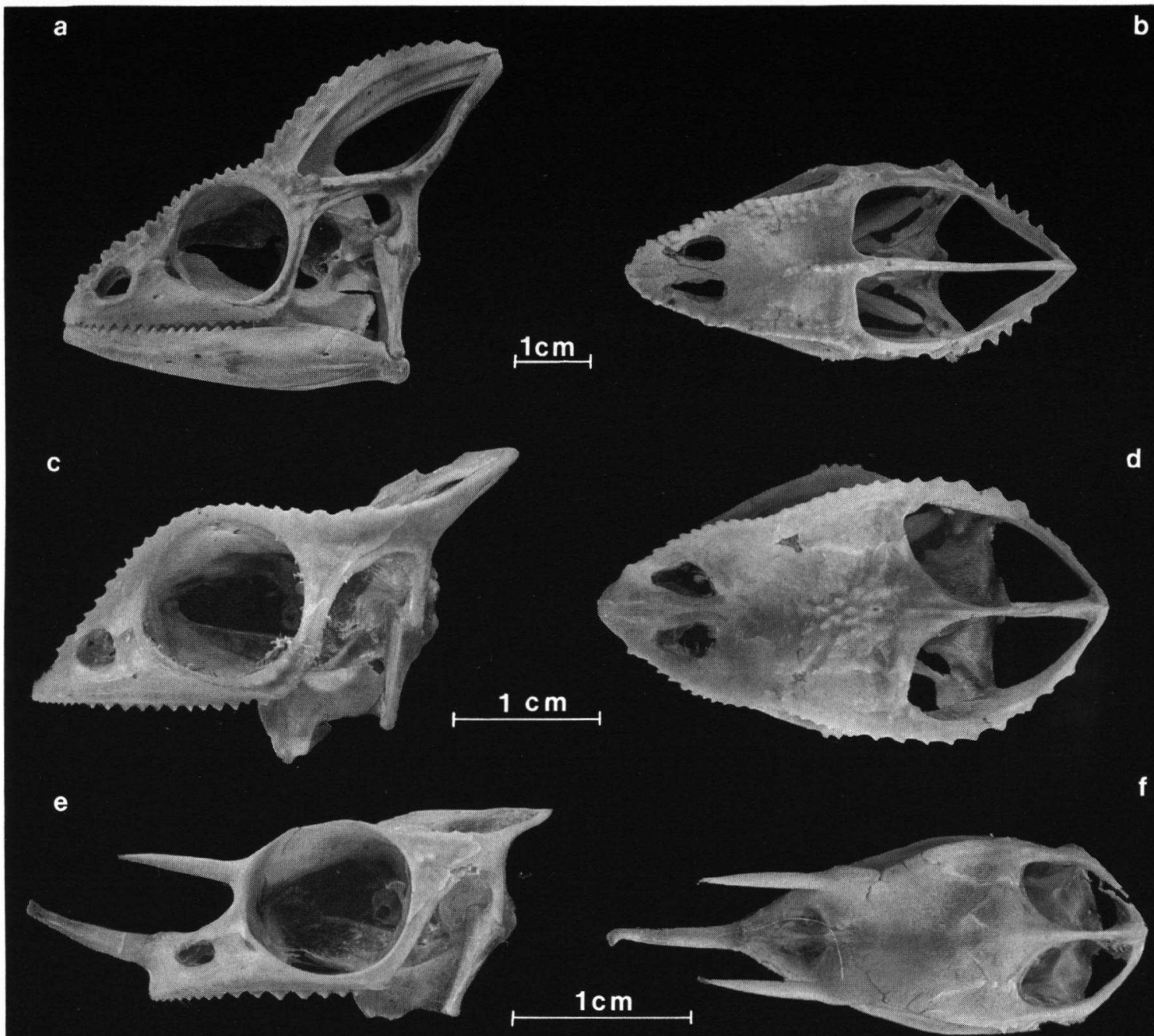

g
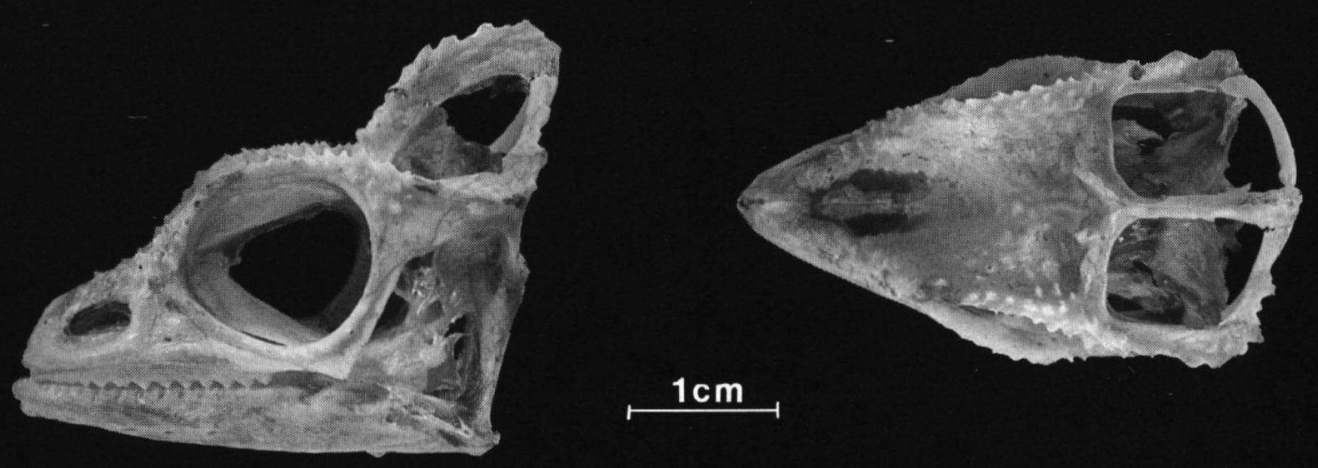

h

Fig. 3. Representatives of species group B, C, E and F, respectively. Left side: lateral view; right side: dorsal view of the same specimen; a $\&$ b: Ch. oustaleti, $\mathrm{c} \& \mathrm{~d}$ : Ch. senegalensis, e $\mathrm{f}: C h$. oweni, $\mathrm{g} \& \mathrm{~h}: C h$. jacksonii. 


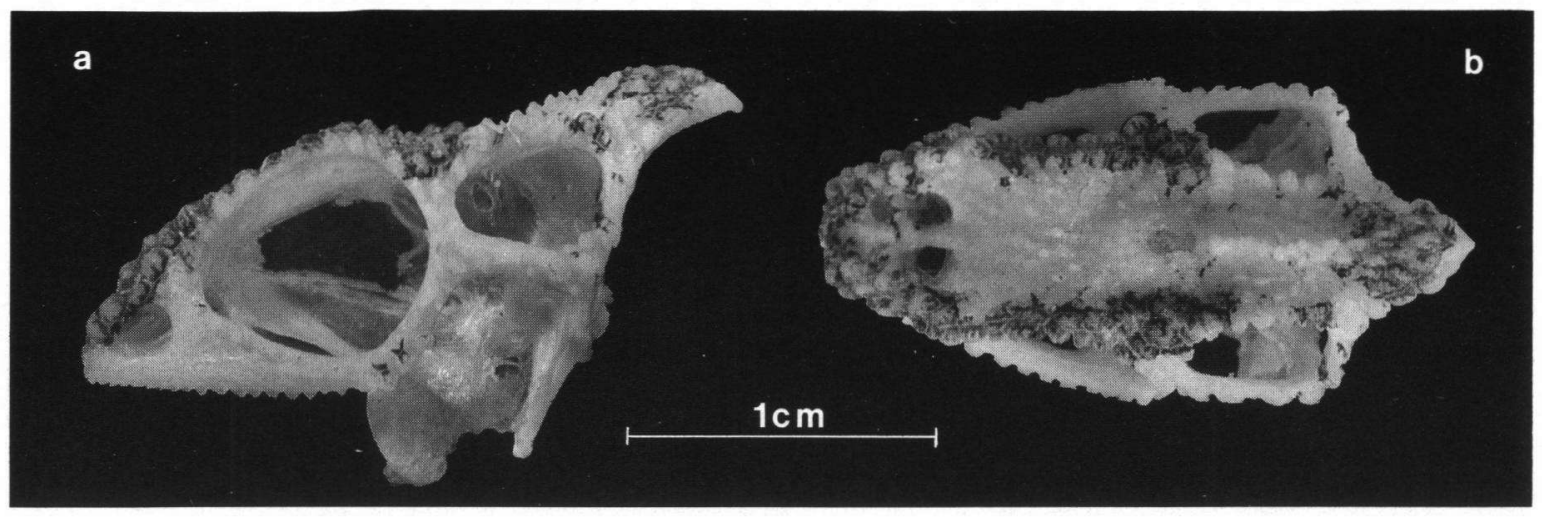

Fig. 4. Chamaeleo pumilus, lateral (a) and dorsal view (b) of the same skull.

1976) to regard pumilus c.s. as belonging to separate genera (Microsaura, Bradypodion etc.). Klaver (1981) argued that such a broad parietal would be a plesiomorphic character but I (1986) pointed out that broad and narrow parietals occur in the related families Iguanidae and Agamidae and that, moreover, Sphenodon Gray, 1872, the very conservative representative of the Rhynchocephalia (Romer, 1956), sister-group of the Squamata, also possesses a narrow parietal, which makes it more probable that a narrow parietal is plesiomorphic. Microcomplement fixation (Hofman et al., in press) also indicates that $C h$. pumilus c.s. are a younger branch within Chamaeleo than the groups C, E and $F$.

The parietal of $C h$. nasutus is trigonal, like that of Rhampholeon. The only difference is that the nasutus skull as a whole is narrower than the one of Rhampholeon. So all Rhampholeon and Ch. nasutus have the following characters in common:

- the trigonal form of the parietal (not occurring in other groups of Chamaeleo),

- the small size (Ch. nasutus and related species are the smallest chameleons, Rhampholeon is even smaller),

- the occurrence of flexible appendages on the snout in some of the species (not occurring in other groups of Chamaeleo),

- axillary pits in some of the species (also present in several other Madagascan species of Chamaeleo),
- inguinal pits in some species (not occurring in other groups of Chamaeleo).

The only important difference between Rhampholeon and Ch. nasutus c.s. is the deviating squamation which Rhampholeon has in common with Brookesia. Brookesia differs from $C h$. nasutus in lacking the flexible appendages on the snout, although the snout of Brookesia nasus may be regarded as more or less similar. Axillary and inguinal pits do not occur in Brookesia and the form of the parietal is somewhat different from that of Rhampholeon and Ch. nasutus c.s., although it is closer to both these groups than to other species of Chamaeleo.

At the end of my 1986 paper I confirmed Klaver's (1979) suggestion that Rhampholeon is intermediate between Chamaeleo and Brookesia. The form of the skull of Chamaeleo nasutus adds more argument to this confirmation.

\section{REFERENCES}

Hillenius, D., 1986. The relationship of Brookesia, Rhampholeon and Chamaeleo (Chamaeleonidae, Reptilia). Bijdr. Dierk., 56 (1): 29-38.

Hofman, A., L. R. Maxson, D. Hillenius \& J. W. ArnTZEN, in press. Immunological evidence pertaining to the taxonomic relationships within the family Chamaeleonidae (Sauria, Reptilia). (Submitted to Amphibia-Reptilia.)

Klaver, Ch. J. J., 1979. A review of Brookesia systematics with special reference to lungmorphology (Reptilia: Sauria: Chamaeleonidae). Bonn. zool. Beitr., 30 (1/2): 162-175. 
- - 1981. Lung-morphology in the Chamaeleonidae (Sauria) and its bearing upon phylogeny, systematics and zoogeography. Z. zool. Syst. EvolForsch., 19 (1): 36-58.

RAw, L. R. G., 1976. A survey of the dwarf chameleons of Natal, South Africa, with descriptions of three new species (Sauria: Chameleonidae). Durban Mus. Novit., 11 (7): 139-161.

ROMER, A. S., 1956. Osteology of the reptiles: i-xxi, 1-772 (University of Chicago Press, Chicago).

Received: 10 April 1988 